\title{
PSICOANÁLISIS Y LA LOGOTERAPIA EN EL TRATAMIENTO DE LA NEUROSIS OBSESIVA
}

\section{Psychoanalysis and Logotherapy in the Treatment of Obsessional Neurosis}

Patricia Ovejas*

\begin{abstract}
Resumen
La integración del Psicoanálisis y la Logoterapia en el diagnóstico y tratamiento de la neurosis obsesiva. El objetivo es analizar de qué manera es posible integrar los aportes del Psicoanálisis y la Logoterapia en el abordaje terapéutico de los neuróticos obsesivos; para lo cual llevó a cabo una revisión sistemática de la bibliografía utilizada, adoptando una perspectiva crítica, y como fuentes primarias se consultaron las obras de Freud, Lacan, y otros autores psicoanalistas y V. Frankl. Una de las conclusiones más importantes es que es posible trabajar con un paciente, en el modelo de un tratamiento psicoanalítico, a través de la transferencia y, desde allí, analizar sus ideas distorsionadas del mundo y de la vida, desde la logoterapia.

Palabras clave: Psicoanálisis, Logoterapia, neurosis obsesiva, tratamiento.
\end{abstract}

\begin{abstract}
The integration of Psychoanalysis and Logotherapy in the diagnosis and treatment of obsessional neurosis. Purpose: Analyze the way the contributions of the Psychoanalysis and Logotherapy may be integrated when dealing with obsessive neurotics in a therapy. Methodology: A systematic review of the literature was conducted, adopting a critical perspective and taking as primary sources Freud, Lacan, Frankl and other psychoanalytic authors'work. Conclusions: It is possible for a patient to undergo a psychoanalytic treatment model through transference technique and, based on that, to analyze his/her distorted ideas of the world and life from logotherapy.
\end{abstract}

Key words: Psychoanalysis, Logotherapy, Treatment of Obsessional Neurosis

\footnotetext{
* Supervisora de los equipos de terapia individual y familiar del servicio de Socialización del Hospital Psicoasistencial J. T. Borda de la Municipalidad de la Ciudad de Buenos Aires. Docente en el Departamento de Psicología de la Pontificia Universidad Católica Santa María de los Buenos Aires. patriciaovejas@yahoo.com.ar
} 


\section{INTRODUCCIÓN}

En 1987, en Viena, en un encuentro personal de la autora con Viktor Frankl, éste le sugirió la importancia de integrar la escuela psicoanalítica y la logoterapia. $\mathrm{Si}$ bien son muchas las patologías que pueden ser abordadas integrando ambos métodos, el presente trabajo se centró sólo en la neurosis obsesiva.

Frente a la subversión de los valores que plantea la postmodernidad, es obligación de los psicólogos dar una respuesta eficiente, siendo necesario para ello que la labor terapéutica se fundamente en 3 ejes claros: (a) La psicoterapia es un proceso tan complejo como el hombre mismo. Solamente conociendo su realidad ontológica, podemos intervenir adecuadamente; de lo contrario, nos arriesgamos a desnaturalizarlo y marginarlo. (b) El conocimiento y la comprensión de la axiología de nuestros pacientes y la colaboración en el proceso a través del cual se hacen responsables de estos valores. (c) Las técnicas atribuidas a distintas escuelas son eficaces cuando se transforman en recursos para abordar al paciente en toda su dignidad de persona única e irrepetible. Generalmente se utiliza una en detrimento de otras y se las aplica en forma disociada e inconexa. Sólo cuando estas afirmaciones hayan sido consideradas, el psicólogo estará capacitado para desarrollar su tarea. Este trabajo pretende ser una contribución a ello.

\section{DEFINICIÓN Y CLARIFICACIÓN DEL PROBLEMA}

El presente artículo es una integración del Psicoanálisis y la Logoterapia en el diagnóstico y tratamiento de los pacientes con neurosis obsesiva. Los aportes del Psicoanálisis permiten comprender su dinámica, génesis y rasgos de carácter, mientras que los aportes de la Logoterapia amplían estos aspectos.

\section{Génesis.}

La neurosis obsesiva se caracteriza por la aparición de ideas, sentimientos o actos que invaden al sujeto, los cuales son vividos como ajenos -egodistónicos-, extraños y hasta patológicos. Aunque el sujeto se esfuerza por despojarlos, se le imponen a su pensar, parasitando al Yo, el que no puede neutralizarlos. Así aparecen las ideas obsesivas y la compulsión a realizar actos indeseables.
En la neurosis obsesiva el conflicto es entre el ello y el superyó, aliados contra el yo. Toda esta sintomatología se despliega en dos campos, el del pensamiento y el de la actividad. Representan las tendencias del Edipo, pero deformadas. A menudo, se puede ver que este complejo constituye el núcleo central de los impulsos rechazados. La situación inicial es la misma que en la neurosis histérica, pero planteada en términos de ambivalencia. La formación de síntomas neuróticos se concibe como el intento de aportar una solución a tal conflicto.

Por la regresión a la fase sádico-anal, surgen tendencias agresivas y destructoras. Aparece la formación reactiva que refuerza la carga libidinal para reprimir dichas tendencias hostiles. Esta es la causa por la cual, la formación del carácter, en el neurótico obsesivo, se encuentra determinada por el erotismo anal y, en particular, por la regresión y fijación a pulsiones sádico-anales y por el mecanismo de formación reactiva operando ante ellos.

En El carácter y el erotismo anal (1908), Freud descubre una tríada con las características de la neurosis obsesiva: (a) ordenados; (b) económicos, hasta la avaricia; (c) tenaces. Esta tríada sería el resultado de la sublimación del erotismo anal y de los mecanismos que operan como producto de la reacción frente a la pulsión anal. También se destacan la pulcritud y la escrupulosidad como reacción frente a lo sucio y a lo perturbador. El obsesivo de potencial psíquico débil está capturado por las fuerzas de sus pulsiones sadomasoquistas. Su persona no consigue constituirse como tal más que a través de una abusiva sumisión a una constricción ideal y abstracta, que hace del hombre obsesivo el dueño absoluto de su propia esclavitud. Él no puede ser él mismo, está preso en el imperativo categórico de una ley ideal que lo lleva a no ser nada.

Desde la más temprana edad, el obsesivo manifiesta sus temores, sus tormentos éticos, la manía del orden y de la meticulosidad. Sienten una necesidad de reglamentar todo y de someterse a prohibiciones rigurosas; son estrictos y avaros.

La neurosis obsesiva le mostró a Freud la existencia de un padre cruel, mítico, que prohíbe a todas 
las mujeres, donde el complejo de castración desempeña un papel esencial. Él mantiene con la ley la misma relación que existe entre la autoridad y el autoritarismo. Más veladamente, pero no con menor eficacia, el superyó materno desempeña su papel; no se desprende fácilmente de lo que considera su propiedad.

La regresión a la fase sádico-anal, producto del rechazo a la fase fálica, puede traducir regresivamente impulsos eróticos amorosos en crueles pensamientos que el consternado yo rechaza de plano.

En la histeria, las ideas reprimidas permanecen inalteradas en el inconsciente y, desde allí, continúan ejerciendo su influencia. En la neurosis obsesiva, los deseos incestuosos son deformados. Se encuentran, constantemente, tendencias a la crueldad, francas o encubiertas, y formaciones reactivas contra ellas. En los síntomas obsesivos, junto al complejo de Edipo, actúan regularmente y al mismo tiempo, impulsos anales y sádicos muy poderosos, originados en el período precedente.

La orientación instintiva sádico-anal del neurótico obsesivo es, por lo común, fácil de reconocer en el cuadro clínico. Los neuróticos obsesivos se hallan preocupados por conflictos entre la agresividad y la sumisión, la crueldad y la bondad, suciedad y aseo, desorden y orden. A veces, la orientación sádico-anal se revela únicamente como formaciones reactivas, tales como una bondad sobrecompensada o un exagerado sentimiento de justicia, de aseo, de incapacidad para cualquier clase de agresión o simplemente puntillosidad extrema. La mezcla de formaciones reactivas y brotes directos de tendencias anales o sádicas pueden dar a la conducta del paciente un carácter contradictorio. Los pacientes son simultáneamente ordenados y desordenados, pulcros y sucios, bondadosos y, sin embargo, crueles.

En general los neuróticos obsesivos, tienen rituales escatológicos secretos, que, en parte, son los juegos erótico-anales, y en parte, formaciones reactivas contra dichos juegos.

Estos pacientes están siempre en guardia contra tendencias anales inconscientes mezcladas de hostilidad. La defensa se dirige primeramente contra el complejo de Edipo fálico, sustituyéndolo por el sadismo anal. Luego, la defensa continúa contra los impulsos anales. La neurosis obsesiva aparece después de esa regresión, pero, a pesar del desplazamiento del interés hacia la región anal, el paciente no consigue evitar el temor a la castración. El efecto inmediato de la regresión es doble. El sadismo se combina con la hostilidad edípica dirigida al progenitor del mismo sexo e impone nuevas tareas defensivas al yo. El erotismo anal emergente produce un cambio en los objetivos sexuales y, de este modo, en la conducta de la persona. Frecuentemente, la regresión trae también a primer plano una cantidad mayor o menor de rasgos narcisistas.

El proceso de aprendizaje de los hábitos higiénicos, en la infancia, adquiere gran importancia en el desarrollo de la relación entre el yo del niño y sus impulsos instintivos. Este aprendizaje representa la primera situación en la que el niño puede aprender a postergar o a renunciar a una gratificación instintiva directa, por consideración a las personas que lo rodean y para no perder el vínculo con esas personas significativas. Los mismos recursos usados por el niño para resistir a las fuerzas superiores de sus educadores pueden ser aplicados, más tarde, en la lucha contra su propio superyó. Necesitando la aceptación de los demás, el niño se esfuerza por lograr un sentimiento de superioridad moral que necesita para acrecentar su autoestima.

\section{El carácter sádico anal del obsesivo.}

El sentido del orden, como rasgo de carácter, es una elaboración de la obediencia a sus adultos significativos. Aseo, puntualidad, minuciosidad, corrección, también significan obediencia y representan formaciones reactivas. Estos sujetos, prototipo de la puntualidad, en muchas ocasiones, resultan sorprendentemente impuntuales.

Abraham (1959) dio a conocer numerosos puntos de anclaje en el carácter, traducidos en una perpetua lucha con la contracatexis: por ejemplo, personas que son escrupulosamente pulcras en su vestimenta externa, y en el mismo extremo, desaseadas en cuanto a su ropa interior; otras que mantienen todo lo que les pertenece en un estado muy desordenado, pero que necesitan, de vez en cuando, arreglarlo todo. 
El estudio psicoanalítico del carácter, en esta neurosis, pone de manifiesto un mecanismo de defensa particularmente importante: la formación reactiva de rasgos de carácter que constituyen una especie de oposición sistemática a las pulsiones inconscientes. El comportamiento afectivo del sujeto es simbólico en el sentido de que mantiene, bajo disfraces aparentes, las conductas arcaicas del período sádico-anal. Los rasgos del carácter del obsesivo pueden tomar la forma de aparentes contradicciones.

Sea el que fuere el tipo de carácter obsesivo, se encontrarán, en diversas proporciones, los cuatro puntos cardinales de nuestro esquema: la tendencia a la suciedad, recubierta por su formación reactiva de súper limpieza y la tendencia a la retención de objetos, recubierta por el comportamiento de prodigalidad (Fenichel, 1996, p.335).

En cuanto al aspecto exterior del sujeto, la contención de las emociones, la preocupación por la corrección, resultando un aire rígido, circunspecto, afectado, constituye una verdadera coraza de protección. La careta de hielo, la flema, la altivez, la falta de soltura en los gestos, son otros tantos medios de defensa. Estas ambigüedades se expresan perfectamente con la frase: "Tiene un aire forzado". En toda su actitud, el sujeto parece querer interponer una armadura entre el mundo exterior y su persona.

En la concepción del síntoma como transacción entre el deseo y la defensa, triunfa siempre la cesura.

El neurótico obsesivo guarda una peculiar relación con sus deseos, se defiende tenazmente de ellos los posterga hasta lo imposible, duda entre dos tendencias hasta paralizarse [...] Pareciera no poder soportar que éstos se realizaran [...] lo anhelado largamente en la fantasía parece perder su encanto cuando el sujeto se encuentra a las puertas de obtenerlo [...] Pueden estar distantes de sus máximas realizaciones de deseo [...] Si finalmente ha concretado sus logros, puede sentirse un espectador de sí mismo (Fenichel, 1996, p.341).

Vale decir que la defensa puede actuar, aun cuando el deseo se concrete. El desapasionamiento forma parte del cuadro clínico. Es que no debemos pensar al deseo como un deseo puro, genuino; le faltaría el permiso para poder realizarse. El deseo obsesivo se encuentra contaminado por las ramificaciones del complejo de Edipo y la regresión. La sombra del objeto incestuoso y la regresión cayeron sobre el objeto del deseo. El deseo se configura como prohibido y el sujeto no dejará de defenderse de éste, arrastrado, por el fantasma incestuoso, a sus más caros y genuinos proyectos. Mientras que, en la histeria, el cuerpo es el escenario del síntoma, en la neurosis obsesiva, el escenario será el yo. El obsesivo teme al castigo de la castración porque se sabe culpable de desear incestuosamente.

Fischer sostiene que "la obsesión no es una neurosis masculina, sino una neurosis que guarda con la masculinidad una relación de mutua exclusión" (1983, 1996, p.132). En Inhibición, síntoma y angustia (1926), Freud explica que constituye una contradicción interna el que, precisamente, en aras de conservar la masculinidad (angustia de castración), se coarte todo el quehacer de ella. Es que la pregunta del obsesivo es qué es ser padre. Tiene una imagen de un padre que no obra según su deseo o un padre que se presenta inalcanzable, que no admite ningún error, que marca un destino imposible de cumplir. En todos los casos, es un padre que le transmite, como deuda, todo aquello que no logró o todo aquello que, según él, debe lograr. Tiene un padre del que no se puede separar, no puede ir más allá de él. Habrá sumisión o rivalidad. Es un padre que falla, un padre deudor. Por ello, el obsesivo no soporta fallar, anula la limitación, se desvive para que todo esté perfecto, trata de anular la limitación como si fuera inmortal. Mata su deseo y se somete al deseo del otro. Son los típicos hijos que se quedan eternamente cuidando a sus padres, o ayudando a algún hermano necesitado. No viven su propia vida. Siempre tiene tiempo para todos, pero lo suyo es postergable. La característica del obsesivo es no concluir nada de lo que se propuso para sí mismo. No decide, la vida le pasa por el costado. Es un muerto con vida. Su vida esta tan paralizada, que se transforma en muerte. No es protagonista de la escena, mira desde afuera cómo se suceden las cosas. Debe permanecer fuera de la escena para permanecer invulnerable. No soporta que a sus seres queridos les falten cosas, vive para cumplirles los deseos de otros, pero no soporta sus 
propios deseos. Se siente culpable o glorioso, necesitando garantes de las cosas que hace bien. Busca protectores, amos a los que se somete; no está dispuesto a arriesgar, a errar; elige una vida sin riesgos, por eso, se pone al servicio del otro, su deseo pasa a ser cumplir el deseo del otro.

El sentido de la defensa frente a la castración, la impotencia y la eyaculación precoz deben ser entendidas en una misma secuencia. El sentido de la eyaculación precoz no es otro que el de la puesta fuera de juego del pene: no busca el placer sino el irse rápido del objeto incestuoso. Es que la mujer ha quedado maternizada. Existen otras modalidades de defensa sobre la sexualidad incestuosa, por ejemplo: cuando la escena sexual es evitada por completo, o también cuando se hace la división: una mujer sagrada para amar y respetar, y otra para degradarla deseándola sexualmente. El sujeto no puede desear allí donde ama, y no puede amar donde desea, dado que ambos objetos reconocerán un mismo origen: la madre. Una deriva de la madre idealizada, otra de la madre que ha desilusionado al celoso varoncito cuando discierne que tiene relaciones con el padre; de aquí surgirá un cierto desprecio hacia ella. La angustia de castración puede presentar efectos desbastadores sobre la organización sexual, y tiende a sacar al obsesivo del amor.

\section{La moralidad en el obsesivo}

La moralidad exigida por el arcaico superyó del neurótico obsesivo es una pseudomoralidad automatizada. El yo hace una concesión a un impulso instintivo y deberá prestarse a exigencias de expiación; una vez cumplida la expiación, el yo puede hacer uso del acto de expiación como una autorización para embarcarse en nuevas transgresiones. Ocasionalmente, el yo se muestra dispuesto a tomar sobre sí castigos y actos de expiación e incluso de tortura que alcanzan extremos sorprendentes. Este masoquismo moral parece ser un complemento del sadismo del superyó. La necesidad de castigo del yo está subordinada, en general, a una necesidad de perdón.

La conducta moral de un paciente obsesivo es determinada, a menudo, por el respaldo que halla en las seguridades recibidas de otra persona, a fin de conservar su propia autoestima.
Temeroso de perder la protección de su propio superyó, de verse compelido a despreciarse a sí mismo, necesita de otra gente como medio indirecto para obtener un alivio. Es una moral heterónoma.

Para Freud la base inconsciente del concepto de justicia es:

Aquello que no me es permitido hacer a mí, tampoco debe permitirse a ningún otro que lo haga. El afán de justicia tiene su raíz en la tendencia a mantener una prohibición, mediante la insistencia en que ésta debe extenderse también a todos los demás. Hay una relación entre justicia y simetría (Fischer, 1983, 1996, p.132).

En casos extremos, la conducta del paciente puede perder, en cierto momento, todo carácter de autenticidad. Haga lo que haga, parece estar ante un jurado, que existe en su fantasía.

\section{El pensamiento en la neurosis obsesiva}

La regresión hacia el sadismo anal y el constante conflicto con el superyó ejercen una influencia característica sobre los procesos del pensamiento en el neurótico obsesivo. Éstos terminan por ser atravesados o suplantados por su precursor arcaico: la palabra.

Las representaciones de las cosas tienen las características de las cosas, y constituyen bienes. Son controladas por el yo; constituyen un intento de dotar a las cosas de cualidad de yo, con el propósito de consumar el dominio sobre ellas.

El neurótico obsesivo, siendo temeroso de sus emociones, teme a las cosas que provocan emociones. Huye del macrocosmos de las cosas al microcosmos de las palabras. Trata de huir de las cosas que provocan emoción hacia las sobrias palabras, pero lo rechazado vuelve y las sobrias palabras dejan de ser sobrias. Son investidas de una sobrecatexis emocional y adquieren el valor emocional que, para las otras personas, asumen las cosas. Cabe recordar que, las primeras palabras, aprendidas en la infancia, son mágicas y omnipotentes. En la neurosis obsesiva, el pensamiento y el habla se han hecho sustitutos de las emociones vinculadas a la realidad; recobran sus cualidades originarias, se 
sexualizan y pierden su valor para el uso práctico. Una vez más, las palabras se vuelven poderosas bendiciones y maldiciones. En un aspecto, obtiene éxito del hecho de retirarse de la esfera del sentimiento a la del pensamiento: el pensamiento compulsivo es pensamiento abstracto -aislado del mundo real de las cosas concretas- y general -orientado hacia la sistematización y la categorización-. Pero, en otro aspecto, fracasa: las escisiones y contradicciones, de que se ve impregnada la vida emocional de los neuróticos obsesivos, se desplazan hacia los (sexualizados) problemas intelectuales, y los resultados son la cavilación y la duda obsesivas. La duda es un conflicto instintivo desplazado al terreno intelectual. Ciertas dudas obsesivas esconden un carácter un poco más simple. Algunas dudas son sobre la validez de las propias percepciones y juicios. El síntoma, relativamente frecuente, de la duda obsesiva, respecto a noticias de muerte, consiste, ante todo, en un temor a la omnipotencia de los propios pensamientos. No se debe discutir nunca con los neuróticos obsesivos sus problemas obsesivos. El analista no debe fortalecer los mecanismos de aislamiento del paciente. Será objeto del análisis, en tanto los pensamientos del paciente permanezcan aislados de sus emociones, el aislamiento mismo, y no el contenido de lo que ha sido aislado. Cuando el paciente intelectualiza, no debemos contrarrestar sus argumentaciones; hay que esperar, para ello, el momento adecuado.

El pensamiento es una preparación para la acción. Las personas que temen a la acción aumentan los preparativos, en vez de actuar, más bien, piensan. Los neuróticos obsesivos constantemente hacen preparativos para el futuro y nunca viven el presente. Muchos síntomas compulsivos tienen el carácter de preparativos para un futuro que nunca se transforma en presente. La causa principal de los exagerados preparativos es ciertamente el miedo a la cosa real. El miedo a cualquier cambio de la situación presente, conocida, por un estado de cosas nuevas, que puede ser peligroso, hace que los pacientes se aferren incluso a sus síntomas. Tal actitud engendra, a menudo, una resistencia latente, que limita las posibilidades de un análisis que, de otro modo, se desarrollaría con éxito. Para el paciente, la neurosis representa, en este caso, una vieja amistad. Algunas formas de reacción -terapéutica negativa- al tratamiento analítico expresan ese temor a todo cambio. El miedo al cambio puede ser reemplazado o acompañado por lo contrario: una tendencia a cambiar continuamente. Por ello, algunos neuróticos obsesivos manifiesten la tendencia a cambiarlo todo, en todas partes, en el intento de adaptar el mundo a su sistema.

La sobrevaloración del intelecto hace que los neuróticos obsesivos logren, a menudo, un alto desarrollo intelectual. Esta elevada inteligencia ostenta, sin embargo, rasgos arcaicos y está llena de magia y superstición. Su yo sufre un desdoblamiento: una parte es lógica, la otra, mágica. El mecanismo defensivo del aislamiento hace posible el mantenimiento de tal desdoblamiento (Fenichel, 1996, p. 331).

Los niños que, convencidos por la realidad, se ven obligados a renunciar a creer en la propia omnipotencia, creen, en cambio, en la omnipotencia de los mayores que los rodean. También persisten, en los neuróticos obsesivos, huellas de esta idea de la omnipotencia de los mayores. Más adelante, esta cualidad de omnipotencia es desplazada de los adultos a Dios. Difícilmente, hay una sola neurosis obsesiva sin rasgos religiosos. La sintomatología y el pensamiento de las neurosis obsesivas está llena de supersticiones mágicas, temen el efecto mágico de las palabras de los demás, actúan como si creyeran en fantasmas, demonios y, especialmente, en un destino muy maligno. Sin embargo, en otros aspectos, son personas inteligentes, completamente conscientes de lo absurdo de estas ideas. En algunos casos, la fantasía no sólo sustituye a una realidad desagradable, sino que, incluso, niega la realidad -mágicamente percibida- en su totalidad.

El paciente no solamente se siente compelido a guardar él mismo un orden sistemático, sino que pretende también de otras personas la aceptación del mismo sistema. Los demás, por lo general, se niegan a someterse a su sistema. Esto aumenta su hostilidad y le hace intentar diversos recursos para obligar a los que lo rodean a proceder como él quiere. La situación se vuelve más compleja cuando el sistema de un neurótico obsesivo choca con los sistemas de otros neuróticos obsesivos. La neurosis obsesiva tiene su base en un erotismo anal intensificado, que a su vez se halla determinado, en parte, por factores 
constitucionales, por lo que, frecuentemente, se manifiestan en una misma familia varios casos de neurosis obsesiva. Esto puede dar lugar a graves contrariedades familiares. No obstante, el apego de los pacientes a sus sistemas no significa, de ningún modo, que sean capaces de cumplirlos.

Los neuróticos obsesivos padecen la tendencia a hacer falsas generalizaciones, a clasificar apresuradamente todas las ideas en ciertas categorías que se excluyen mutuamente, y caer luego en un estado de duda sobre la naturaleza y la valoración de las categorías. El neurótico obsesivo es ambivalente, incluso, frente a sus propios sistemas y reglas. Cuando toma partido contra sus impulsos instintivos peligrosos, necesita protegerse con sistemas y reglas. Cuando se vuelve contra su superyó, se enfrenta también contra sistemas y reglas impuestos por el superyó. Puede rebelarse abiertamente contra ellos o ridiculizarlos mediante la reducción al absurdo. El obsesivo, por un lado, se somete a un amo y, por otro, se revela a toda autoridad. Se esfuerza por dominar el mundo y se justifica mediante la razón.

\section{SÍNTESIS DE INVESTIGACIONES PREVIAS}

Freud, en A propósito de un caso de neurosis obsesiva ("el Hombre de las Ratas"), expresa que el paciente distorsiona su idea filosófica del universo (1909). Frankl describe cómo se distorsionan de manera particular la idea del mundo y de la vida en cada neurosis de transferencia. La integración, para su tratamiento, del Psicoanálisis y la Logoterapia, es posible a partir del concepto de transferencia. Para Freud, constituye un elemento fundamental para el diagnóstico y para el tratamiento de las neurosis. Para Frankl esta distorsión es causada, entre otras cosas, por el conflicto neurótico y debe ser abordada dentro del tratamiento para que éste no quede a mitad de camino (Ovejas, 2005).

\section{IDENTIFICACIÓN DE RELACIONES}

\section{Tratamiento de la neurosis obsesiva}

Con fines didácticos se han desarrollado por separado los aportes del Psicoanálisis y de la Logoterapia al tratamiento de estas neurosis. Sin embargo, cabe aclarar que se interviene simultáneamente desde ambas escuelas.

\section{El aporte del psicoanálisis al tratamiento de la neurosis obsesiva}

\section{Manejo del encuadre.}

Estas personalidades se hallan también perturbadas en su actitud frente al tiempo y al dinero: pueden ser tacaños o pródigos, puntuales o impuntuales, exactos hasta una fracción de minuto en algunas ocasiones e irresponsables en otras. En la neurosis obsesiva, la represión ha transformado la relación del paciente con el tiempo y con el dinero en un campo de batalla donde se dirimen sus conflictos instintivos. La conducta de estos neuróticos está impregnada de manifestaciones de sadismo o de formaciones reactivas contra el sadismo. Todo equilibrio entre dar y tomar les resulta imposible. Ningún neurótico obsesivo es capaz de manejar racionalmente el dinero y el tiempo. El dinero se convierte en un objeto de placer (o de castigo). Puede ser irracionalmente retenido o irracionalmente derrochado, o bien las dos conductas opuestas se combinan.

El neurótico obsesivo se siente protegido, mientras se comporte de una manera ordenada, especialmente, en lo que se refiere al dinero y al tiempo. Esto se manifiesta en el manejo del encuadre psicoterapéutico, donde controlan los minutos de duración de la sesión, la puntualidad del terapeuta, les cuesta pagar o se desesperan si no pagaron la sesión.

\section{Trabajo con la transferencia}

Fuera de algunas contraindicaciones bastante precisas, el tratamiento de la neurosis obsesiva es el psicoanálisis. No obstante, este tratamiento resulta aquí particularmente largo y difícil. La transferencia, en el obsesivo, está captada por la ambivalencia de todas sus relaciones. Esto marca la importancia de integrar al tratamiento psicoanalítico de estos pacientes la logoterapia.

La obstinación del paciente, su tendencia a racionalizar y a discutir cada punto, sus exacerbadas defensas contra toda emoción, actúan como obstáculos en el juego de las asociaciones libres, ya que el análisis 
debe alcanzar naturalmente el nivel de las estructuras pregenitales, lo cual lo hace largo y multiplica las acechanzas.

Cuando comienza el tratamiento, los rasgos de su personalidad se manifiestan en la transferencia. Sus defensas están interpuestas para controlar y retener el encuadre, el pago de la sesión y la atención del terapeuta. Intelectualiza el significado profundo de lo afectivo. Retiene todo el material emocional. Su exagerado formalismo resulta agobiante; se pierde en los detalles sin importancia y, en ocasiones, le resulta imposible evitar el bostezo. Se obliga a una perfección abrumadora, se cuida todo el tiempo de no errar y expresar lo justo, reitera cada frase, cada pensamiento. Su miedo al descontrol obstaculiza la aparición de contenidos afectivos; cuando estos aparecen trata de explicarlos.

El obsesivo produce una impresión contratransferencial de aburrimiento y de tensión particular que fatiga rápidamente, por el alto interés que exige y por la sensación de atención no satisfecha que se recibe. La presentación, su vestimenta, su atildamiento, su gesticulación rígida, despojada de gracia, suelen llamar la atención. El paciente realiza, en la transferencia, una relación muerta con el analista. El paciente está en el ir y venir del control de las emociones y desafectiviza las palabras.

Las interpretaciones no resultan muy efectivas por el aislamiento. Las intervenciones en acto sobre la transferencia son la herramienta psicoanalítica más efectiva. El analista no dispone de una conciencia espontánea de los acontecimientos patógenos de la infancia, faltan las emociones correspondientes. Las intervenciones, desde el psicoanálisis, se encuentran limitadas por este mecanismo, y cuando son posibles, son costosas y a largo plazo.

El aporte de Freud es indispensable para el diagnóstico y para la comprensión dinámica de esta neurosis, pero el tratamiento requiere la integración con la logoterapia.

El aporte de la Logoterapia al tratamiento de las neurosis obsesivas.

Viktor Frankl define a su corriente como una terapia inespecífica en el tratamiento de las neurosis de transferencia, ya que para él, el psicoanálisis es la corriente específica para abordarlas (1978). Define así su método como de complementación con la escuela creada por Freud (Oro, 1985).

Existe, ante la neurosis compulsiva, una logoterapia especial, que se propone abordar, concretamente, la curación mental específica del neurótico compulsivo y corregir aquella concepción del mundo característica a la que esta clase de neuróticos propenden típicamente (Frankl, 1978, p. 253).

Podría decirse que los neuróticos obsesivos tienen la manía de dudar, se sienten torturados por la sensación de que queda algún residuo sin aclarar. Experimentan la necesidad de seguir indagando. Por ello, puede hablarse de una insuficiencia en el sentimiento de evidencia en estos neuróticos. A esta alteración, en cuanto al conocer, corresponde, en el área de las decisiones, una alteración de la seguridad instintiva. Aparece trastornada aquella seguridad instintiva que acompaña, en la vida diaria, al hombre normal, que reserva la conciencia de su responsabilidad para las grandes decisiones de su vida. La alteración de la propia seguridad instintiva, en el conocer y en las decisiones conduce, a esta clase de neuróticos a un control forzado de sí mismos. Provoca, por ley de compensación, la voluntad de llegar a una seguridad absoluta en sus conocimientos y sus decisiones. El neurótico obsesivo aspira a lo total, al ciento por ciento, busca lo absoluto, lo que nunca falla, enfrenta al mundo como totalidad, y padece profundamente el carácter problemático de cada una de sus decisiones. Como afirma Frankl:

El fundamento del mencionado "concepto del mundo neurótico obsesivo del cien por ciento" radica pues en una conmoción que ha cegado aquellas fuentes esencialmente inconscientes que alimentan, en el individuo normal, los actos del conocimiento y de la decisión; por un lado, el sentimiento de evidencia, por el otro, esa seguridad instintiva que funciona en el sector de lo moral como conciencia. Ambos, evidencia e instinto moral, obran desde una esfera espiritual aunque inconsciente (...), el intentarlo, a pesar de todo, constituye la tragedia del individuo neurótico obsesivo: su ansia fáustica fracasa en el intento de racionalizar 
violentamente lo esencialmente irracional (...); en este caso, hemos visto, en forma ejemplar, cuán importante es, en la psicoterapia, hacer conscientes no sólo los complejos inconscientes (en el sentido del psicoanálisis), sino también actitudes espirituales inconscientes (Frankl,1983,p. 126).

El hombre sano ve siempre lo particular, enfoca el mundo en perspectiva. En cambio, en la imagen del mundo del neurótico compulsivo, todo lo concreto cae en un punto ciego; estos pacientes no saben vivir de la manera provisional en que debe vivir el hombre. Se sienten siempre inmersos en una impaciencia específica; los caracteriza cierta intolerancia en lo que respecta al conflicto existencial ante el ser y el deber ser. Esto funciona desde el inconciente del paciente y se debe intervenir terapéuticamente para que lo haga conciente. Como afirma Frankl, en "Psicoanálisis y existencialismo", probablemente su necesidad de perfección sea lo que hizo que Adler hablara del querer igualarse a Dios de estos neuróticos.

... al neurótico obsesivo le anima un impulso fáustico, una voluntad por lo absoluto, la aspiración a un conocimiento absolutamente seguro y una decisión absolutamente justa. El neurótico obsesivo fracasa, igual que Fausto, al experimentar "que en el hombre no hay nada perfecto" (Frankl, 1964, p. 99).

Para la intervención se recurre, en estos casos, a la mayéutica -técnica logoterapéutica-, y se intenta lograr que el paciente que teme equivocarse, que se paraliza buscando la acción perfecta, que no soporta correr el riesgo del error, entienda que no hacer nada, que postergar, "es un error". El neurótico obsesivo huye de lo provisional para buscar lo definitivo; escapa de lo indeterminado para buscar lo definido. La esencia de la neurosis compulsiva podría resumirse en un afán fáustico. El obsesivo, arrastrado por esta voluntad absolutista, por este empeño de buscar en todo siempre el ciento por ciento, viene a ser una especie de Fausto frustrado, trágico y triste por lo que tiene de humano. Por medio del trabajo psicoterapéutico, se debe hacer consciente esta esencia de la neurosis obsesiva que opera desde el inconsciente.
Hay algo que también debemos tener en cuenta: la peculiar actitud espiritual, incluso quisiéramos decir el "concepto del mundo" del neurótico obsesivo típico. Esta actitud está caracterizada por una aspiración del cien por ciento, de lo absoluto. Lo que busca el neurótico obsesivo es la seguridad absoluta en todo, en el conocimiento tanto como en la decisión. Está poseído por una especie de ansia fáustica que lo empuja. El neurótico obsesivo trata de suprimir lo incidental y provisional, adherido a todo conocimiento y decisión como algo humano, como algo inherente a la criatura. Se revela contra la imperfección (Frankl, 1964, p. 125).

Sobre esta peculiar actitud es necesario trabajar en el análisis, mostrándole al paciente, todo lo que pierde por ella. Porque ante la imposibilidad de ver cumplidas íntegramente sus ambiciones totalitarias, no tiene más remedio que completarlas en un pequeño campo; de allí, su marcada tendencia a fijarse en los detalles. Como no puede realizar la totalidad, se circunscribe a un pequeño campo que considera asequible. El paciente puede comprender que su tendencia fáustica a la certeza absoluta está destinada al fracaso ya que:

...el neurótico compulsivo no logra realizar su ambición totalitaria más que de un modo fragmentario o puramente ficticio, y siempre a costa de su naturalidad, o de lo que el hombre tiene de "criatura". Este tipo de hombre se sustrae a la "realidad del devenir", desprecia la realidad como un "trampolín" de la libertad existencial (Frankl, 1978, p. 258).

\section{Evolución de la neurosis obsesiva}

En lo que se refiere a la terapia analítica, la neurosis obsesiva es considerada como el segundo tipo de las neurosis de transferencia y como el segundo gran campo en que se indica el psicoanálisis. La consideración de los mecanismos implicados muestra cuánto más complicado es el análisis en la neurosis obsesiva que en la histeria. Se debiera ser muy cauto respecto a promesas de curación. Es necesario conformarse con un grado más o menos considerable de mejoría; la obediencia a la regla básica será muy difícil o totalmente imposible. Se debe hallar la manera de que el paciente se haga una idea de la sensación de 
asociar libremente $\mathrm{y}$, al mismo tiempo, mantener discusiones utilizando la mayéutica, las argumentaciones contra lógicas o la técnica del denominador común -técnicas específicas de la logoterapia que intentan modificar la idea distorsionada del mundo y de la vida-. Ésta es, tal vez, la principal tarea técnica en el análisis de un neurótico obsesivo, porque el yo está desdoblado. El analista sólo puede apoyarse confiadamente en una parte del yo. El resto del yo piensa de una manera mágica, no sujeta a lógica, y se coloca prácticamente al lado de la resistencia. La parte consciente de la personalidad puede cooperar mucho, pero a medida que esta parte se aísla de la parte inconsciente, mágica, la interpretación mejor concebida resulta ineficaz, a menos que se quiebre ese aislamiento. A su vez, existe siempre el peligro de que el paciente sienta su análisis solamente como una forma de comprensión intelectual. El pensamiento y el habla del neurótico obsesivo son los instrumentos del psicoanálisis. Porque no toda la personalidad de estos pacientes está capturada por el conflicto. El neurótico obsesivo debe ser curado con la ayuda de las funciones lógicas que no se hallan afectadas por la enfermedad.

Esta serie de dificultades no son insuperables, pero no deben ser tampoco subestimadas. A causa de ellas, todo análisis de neuróticos obsesivos constituye una empresa difícil y que toma tiempo; son los casos que requieren los consabidos análisis largos. De todos modos, cabe aclarar que se ha logrado la mejora de estos pacientes, aún en casos de muy larga duración.

Por lo tanto, resulta de gran importancia, en el tratamiento de esta neurosis, la complementación del psicoanálisis, como terapia específica, y de la logoterapia, como terapia inespecífica.

\section{CONCLUSIONES}

En este artículo, se planteó un Freud desafiado por las resistencias; buscando intervenir, pero produciendo transformaciones.

Freud modifica la concepción lineal temporal: el pasado se encuentra en el presente. El niño y la infancia adquieren un nuevo valor por su explicación etiológica de las neurosis (series complementarias). Los puntos de fijación hacen que el sujeto se quede en un modo de carácter infantil, con sus modalidades de defensa, con su manera de vincularse, su forma de pensar y, también, con su idea del mundo y de la vida. Todo este pasado se hace presente, lo cual plasma en su teorización sobre la transferencia. Por ello, la transferencia guarda una íntima relación con la idea que el sujeto tiene del mundo y de la vida.

En todas las corrientes psicológicas, existe una idea de persona y de mundo. Si se sigue una escuela como letra muerta, el mensaje se endurece. Freud habló de su escuela como construyéndose, como no acabada, y dejó en claro, en una carta a Binswanger, que sólo se encargaba de lo instintivo, legándole a él el trabajo sobre lo espiritual: "...me he parado en el sótano y no he salido de allí..." (Frankl, 1956, p. 115); “...la humanidad sabe que tiene espíritu; yo le he venido a mostrar que tiene impulsos..." (Frankl, 1964, p. 191).

Gracias al aporte de Frankl, la situación analítica, que parte de la transferencia, puede convertirse en encuentro: la situación neurótica se desplaza al encuentro analizante-analista, convirtiéndose en una situación dialogal. El problema de algunos psicoanalistas no es reconocer a la transferencia como centro de la relación analítica, sino creer que la psicoterapia es sólo eso, que todo termina allí.

No se puede negar el aporte del psicoanálisis. Las neurosis se pueden tratar de varias maneras. Sin embargo, hay una sola forma de entenderlas en sus dinamismos más profundos y en su génesis: trabajando analíticamente; pero también se modifican las ideas erróneas del mundo y de la vida. La idea de mundo y de la vida de la infancia sigue actuando en la neurosis, y si no se trabaja con ella, lo removido en el análisis se vuelve a instalar.

Para finalizar, se recuerda que psicoterapia etimológicamente significa prestarle atención al alma. Todo analista trabaja en forma más o menos intuitiva con la idea de mundo y de vida de sus pacientes. Por lo tanto, es posible trabajar con un paciente, en el modelo de un tratamiento psicoanalítico, a través de la transferencia y, desde allí, analizar sus ideas distorsionadas del mundo y de la vida, desde la logoterapia. 


\section{REFERENCIAS}

Abraham, Karl (1959). Psicoanálisis Clínico. Buenos Aires: Paidós.

Fenichel, Otto (1996). Teoría psicoanalítica de la neurosis. Buenos Aires: Paidós.

Fischer, Héctor (1983). Las neurosis. Buenos Aires: Centro Editor Argentino.

Fischer, Héctor (1996). Conceptos fundamentales de psicopatología. Buenos Aires: Centro Editor Argentino.

Frankl, Viktor (1956). Erinnerungen a Sigmund Freud. Journal of humanistic Psiychology fall 1966, 6 (2) p. $97-106$

Frankl, Viktor (1964). Teoría y terapia de las neurosis. Madrid:Gredos.
Frankl, Viktor (1978). Psicoanálisis y Existencialismo. México: Fondo de Cultura Económica.

Frankl, Viktor (1983). La psicoterapia en la práctica médica. Buenos Aires: Plantin.

Freud, Sigmund (1908). Obras Completas. Buenos Aires: Amorrortu.

Oro, Oscar (1985). Logoterapia (p.12). Buenos Aires: Publicación de Estudios Franklianos y de la Sociedad Argentina de Logoterapia.

Ovejas, Patricia (2005). Integración de las teorías de Freud y Frankl en el diagnóstico y tratamiento de las neurosis de transferencia. Tesis Doctoral. UCA. Buenos Aires.

Fecha de recepción: 27 de abril, 2011

Fecha de aceptación: 10 de octubre, 2011 